\title{
Risk Factors Associated with Early Pregnancy and Attention Deficit Disorders
}

\author{
Damarys Chacón 0 'farrill $^{1}$ and Alba Cortes Alfaro ${ }^{2 *}$ \\ ${ }^{1}$ Department of Gynecology and Obstetrics, Cuba \\ ${ }^{2}$ Department of Epidemiology, Researcher and Assistant Professor, Cuba \\ *Corresponding author: Alba Cortes Alfaro, Department of Epidemiology, Researcher and Assistant Professor, Cuba
}

\begin{abstract}
ARTICLE INFO
Received: 幽 June 06, 2019

Published: 㓞 June 13, 2019

Citation: Damarys Chacón O`farrill, Alba Cortes Alfaro. Risk Factors Associated with Early Pregnancy and Attention Deficit Disorders. Biomed J Sci \& Tech Res 18(5)-2019. BJSTR. MS.ID.003211.
\end{abstract}

Keywords: Attention Deficit Disorders; Reproductive Risk Factors; Early Motherhood

\section{ABSTRACT}

Introduction: early motherhood is a biological condition that is associated with neurological damage and when interacting with social, economic and environmental factors the susceptibility increases, favoring the development of attention deficit disorders in their children.

Objective: To identify reproductive risk factors in women who had an early pregnancy and who are currently diagnosed with attention deficit disorders.

Method: Descriptive, longitudinal and prospective study with quantum-qualitative approach developed in the Municipality of San José de las lajas. Mayabeque during February- May 2018.

Study Universe: 24 women.

Sample: 20. Primary source of data collection: the survey. Results: predominance of pregnancy during the late adolescence stage $15-19$ years $(90 \%)$, not inserted labor $(60 \%)$, where the relationships of couples are dissolved in $100 \%$, significant presence of diseases that complicated pregnancy, predominance of male sex $(75 \%)$, born by dystocic delivery $(75 \%)$, term and with good weight for gestational age $(90 \%, 100 \%$ respectively).

Conclusion: Preconceptional, obstetric and perinatal risk factors may favor the development of attention deficit disorders in early pregnancy.

\section{Introduction}

Adolescence is a period of development and growth during which people establish their sense of individual identity, modification of the personal scheme, adaptation to more mature intellectual capacities, to the demands of society, internalization of a personal value system and preparation for adult roles. It is established between the ages of 10-19 years. Adolescent pregnancy is a major concern of the Cuban Health System [1,2]. The problem of pregnancy in adolescence does not have a specific cause but is multifactorial. Several authors highlight in this group, biological and psychosocial risk factors [3,4]. Motherhood in adolescents means risk to your health and that of your child. The pregnant woman may develop hypertensive disease of pregnancy, urinary or vaginal infections and preterm delivery. In newborns, complications are related, among others, to low birth weight, prematurity and lead to neurological damage [5-8].

Attention deficit disorder is a relatively new name for a pathology described since the $16^{\text {th }}$ century. With specific therapy since 1955. It was a disorder that initially only arose in children, as it is a common disease that affects 7 percent of school children but is currently considered to be evolving into adulthood [9]. The fundamental symptoms are effect of attention, nervousness, impulsivity, difficulty in planning, among others. It is a clinical entity that often has a comorbid behavior with affective disorders, substance use, learning disorders among others. Currently the treatment includes both psychotherapeutic and pharmacological aspects, both having the same level of importance [8]. Because 
of its impact on both children and adults, it is currently a topic of great interest on which many studies are conducted worldwide. This research was carried out with the objective of identifying the reproductive risk factors in women with a history of early motherhood and who currently have their children diagnosed with attention deficit disorders.

\section{Method}

Descriptive, longitudinal and prospective study with a quantumqualitative approach. The universe was made up of 24 women. with antecedent of early maternity and children with diagnosis of TDH with file from April 2017 to 2018 for the treatment with Methylphenidate. The study was conducted with a sample of 20 patients from the municipality of San José de las Lajas. Mayabeque during February to May 2018.

\section{Inclusion Criteria}

a) Willingness to participate in the study.

b) Women with a history of teenage pregnancy, children under treatment with Methylphenidate due to a diagnosis of ADD, living in the municipality of San José de las Lajas, Urban Area (Table 1).

Table 1: Age and schooling during pregnancy. San José de las Lajas Mayabeque February - May 2018. P=0,3292.

\begin{tabular}{|c|c|c|c|c|c|c|c|c|}
\hline \multirow[t]{3}{*}{ Age } & \multicolumn{8}{|c|}{ Scholarship } \\
\hline & \multicolumn{2}{|c|}{ High school Basic } & \multicolumn{2}{|c|}{ Technical professional } & \multicolumn{2}{|c|}{ Pre-university } & \multicolumn{2}{|c|}{ Total } \\
\hline & No & $\%$ & No & $\%$ & No & $\%$ & No & $\%$ \\
\hline \multicolumn{9}{|l|}{$14-16$} \\
\hline & 2 & 10 & - & - & - & - & 2 & 10 \\
\hline \multicolumn{9}{|l|}{$17-19$} \\
\hline & 8 & 40 & 6 & 30 & 4 & - & 18 & 90 \\
\hline \multicolumn{9}{|l|}{ Total } \\
\hline & 10 & 50 & 6 & 30 & 4 & 20 & 20 & 100 \\
\hline
\end{tabular}

\section{Exclusion Criteria}

a) Express wish to refuse to participate in the study.

b) Do not obtain reliable maternal or newborn data.

\section{Bioethical Aspects}

Communication to the Scientific Council of the institution. All people were treated equally, regardless of their physical condition and cultural level. No disclosure and confidentiality of the name of the patients involved in the study. The data is used for scientific purposes, presentation at events and its publication

\section{Techniques and Procedures:}

\section{The data is Obtained From:}

a) Analysis of the current records (April 2017-2018) of children treated with methylphenidate in the main municipal pharmacy San José de las Lajas, Mayabeque.

b) Obstetric and pediatric history in the doctor's offices of the Luis Augusto Turcios Lima and Rafael Echezarreta Mulkay polyclinics family, San José de las Lajas, Mayabeque.

c) Interview and questionnaire to the mothers.

\section{Statistical Processing}

a) For the Quantitative Approach: Use of data base Microsoft Excel Office 2007.

b) Use of elements of Descriptive Statistics: calculation of absolute frequency (FA) and relative (\%) and c) Inferential Statistics: Pearson's Chi-square test by using the program for analysis Epidemiological data tabulated, version 3.1 (EPIDAT). The results are expressed in tables.

d) Qualitative Approach: By means of questions: Semi-structured interview, information necessary for the investigation was collected. The registration process to conserve them was done through notes and recordings. The union of both approaches allowed deepening on the subject investigated.

\section{Results}

During late adolescence, gestation occurred in 90\% (between 17-19 years) with an educational level of Basic Secondary Education by $50 \%$. It was obtained during the interview that $100 \%$ did not continue studies and that currently $60 \%$ are housewives.

Regarding Marital Status: 2 were single mothers (10\%) and $90 \%$ of pregnant women were accompanied. Currently $100 \%$ are separated from the parents. Among the risk factors, it was observed that they presented a history of psychiatric disorders or psychological disorders 3 women (15\%) and poor socioeconomic conditions and biological factors (history of chronic arterial hypertension) in $20 \%$ respectively (Table 2 ). It should be noted that the association of biological factors and poor socioeconomic conditions were related in $75 \%$. It is appreciated that hypertensive disorders were represented by Preeclampsia/Eclampsia in 15\%, anemia, placenta previa and alteration of the amniotic fluid (oligohydramnios) in $10 \%$ and 1 pregnant woman (5\%) presented 
urinary tract infection. It is appreciated that hypertensive disorders were represented by Preeclampsia/Eclampsia in 15\%, anemia, placenta previa and alteration of the amniotic fluid (oligohydramnios) in $10 \%$ and 1 pregnant woman (5\%) presented urinary tract infection. It is significant that $90 \%$ at term with adequate weight for gestational age, 2 newborns were preterm and low birth weight (10\%).

Table 2: Marital status at the time of pregnancy and current relationship with the father figure. San José de las Lajas Mayabeque February - May 2018.

\begin{tabular}{|c|c|c|}
\hline Marital Status of the Moment of Pregnancy & Number & Percent \\
\hline Single & 2 & - \\
\hline Married & - & 90 \\
\hline Accompanied & 18 & 100 \\
\hline Total & 20 & 90 \\
\hline
\end{tabular}

\section{Discussion}

The recognition of the risk posed by teenage pregnancy is a real problem, a cause of concern for dissimilar health professionals dedicated to its study [9]. Among the variables analyzed are age, since adolescence is a stage in which the organism is under biological, social and psychological transformations (Table 3). These changes favor alterations during pregnancy, with the likelihood that they are closer to the gynecological age and therefore in early or middle adolescence [10]. One of the characteristics of couple relationships during adolescence is the instability of couples, favoring concealed and unplanned pregnancies (Table 4), which increases the likelihood of single mothers, with frequent breakups in couples' relationships and in this research it demonstrates. There are studies that suggest that this favors conflict and / or hostility in the parent-child interaction and associates with the aggressive behavior of these children and becomes more aggravated during adolescence $[1-3,11]$. This stage of life coincides with the school, going through the continuity of study, which is truncated, school dropout is frequent, due to early pregnancy, in fact in the research no woman continued the professional improvement after pregnancy (Table 5).

Table 3: Preconceptional risk factors: Bio-psycho-social during pregnancy. San José de las Lajas Mayabeque February - May 2018.

\begin{tabular}{|c|c|c|}
\hline Risk factors & Number & Percent \\
\hline Biological: Pathological antecedents of chronic arterial hypertension. & 4 & 20 \\
\hline Psychological: psychological and psychiatric disorders & 3 & 15 \\
\hline Bad socio-economic conditions & 4 & 20 \\
\hline
\end{tabular}

Table 4: Associated diseases that complicated the pregnancy. San José de las Lajas Mayabeque February - May 2018.

\begin{tabular}{|c|c|c|}
\hline Diseases Associated with Pregnancy & Number & Percent \\
\hline Preeclampsia/Eclampsia & 3 & 15 \\
\hline Anemia & 2 & 5 \\
\hline Urinary tract infections & 1 & 10 \\
\hline Previous placenta & 2 & 10 \\
\hline
\end{tabular}

Table 5: Delivery routes and APGAR score in newborns. San José de las Lajas Mayabeque February - May 2018. $\mathrm{p}=0,0022$.

\begin{tabular}{|c|c|c|c|c|c|c|}
\hline \multirow{3}{*}{ Birth pathways } & \multicolumn{6}{|c|}{ APGAR Score } \\
\hline & \multicolumn{2}{|c|}{ APGAR normal } & \multicolumn{2}{|c|}{ APGAR normall } & \multicolumn{2}{|c|}{ Total } \\
\hline & No & $\%$ & No & $\%$ & No & $\%$ \\
\hline Eutoxic & 5 & 25 & - & - & 5 & 25 \\
\hline Dystocic Caesarean section & 9 & 45 & 2 & 10 & 11 & 55 \\
\hline $\begin{array}{c}\text { Dystocic } \\
\text { Instrument }\end{array}$ & - & - & 4 & 20 & 4 & 20 \\
\hline Total & 14 & 70 & 6 & 30 & 20 & 100 \\
\hline
\end{tabular}


It corresponds to other research in pregnant adolescents, where early pregnancy affects their educational process, frustrating in most cases their life projects. The low educational level and the abandonment of the studies are very imbricated because one leads to the other [12]. People with low educational level generally do not react in a rational and logical way to situations that are characteristic of the crisis of the stages of the family's life cycle, and in the adolescent it is increased by not being able to make adequate decisions, in which they can be present feelings of insecurity and uncertainty aggravating psychological or psychiatric disorders that could have as background [13]. Among the non-neurobiological factors involved in the origin of ADD, psychosocial risk factors have been described that would influence the development of emotional and cognitive control capacity (Table 6). Problems in the family relationship are more frequent in families of children with ADD. This can be a consequence or a risk factor by itself [14].

Table 6: Birth weight and gestational age of the neonates. San José de las Lajas Mayabeque February - May 2018.

\begin{tabular}{|c|c|c|c|c|c|c|}
\hline \multirow{3}{*}{ Birth weight (grams) } & \multicolumn{6}{|c|}{ Gestational Age at Birth } \\
\hline & \multicolumn{2}{|c|}{ Preterm } & \multicolumn{2}{|c|}{ Finished } & \multicolumn{2}{|c|}{ Total } \\
\hline & No & $\%$ & No & $\%$ & No & $\%$ \\
\hline-2500 grs & 2 & 10 & - & - & 2 & 10 \\
\hline 2500 o más grs & - & - & 18 & 90 & 18 & 90 \\
\hline Total & 2 & 10 & 18 & 90 & 20 & 100 \\
\hline
\end{tabular}

Note: Yacht Correction: 0.0012

The present study does not correspond to investigations carried out where newborns predominate with intrauterine and preterm growth restriction. Yes, it was present conditions that may contribute to intrauterine ischemic hypoxia as hypertensive disorders during pregnancy, corresponding with studies suggesting that the adverse effect of hypoxia and ischemia on prenatal brain development can lead to functional problems, such as ADD14twenty [15-19]. Other studies indicate that the absence of a parent and the improper performance of roles in the case of adolescents are also predisposing factors that favor the early and timely diagnosis of neurodevelopmental disorders and by associating with psychosocial and environmental factors such as Inadequate socioeconomic situation or psychosocial stress of the family due to disorganization crisis, attention deficit disorders may arise [20-25].

\section{Conclusion}

Reproductive risk factors in the preconceptional stage, such as obstetric and perinatal risks, may favor the development of ADD in early pregnancy, whether these are bio-socio-economic factors.

\section{References}

1. Cruz Sànchez F, Rodriguez Alonso B, Alonso Urías RM (2014) Childcare during adolescence. Maternal and Child Department, Ministry of Public Health of Cuba pp. 185-190.

2. Borrás T (2014) Adolescence: definition, vulnerability and opportunity, Havana.

3. Álvarez Sintes (2008) Comprehensive General Medicine. (2 $2^{\text {nd }}$ Edn), Havana: Editorial Medical Sciences pp. 2504.

4. Peláez Mendoza J (2012) Pregnancy in adolescence, a pending subject. Rev Cubana obstet Ginecol 38 (4):1

5. Pérez Rosabal E, Soler Sánchez, Pérez Rosabal R, Marlenes Fonseca Ménde L (2015) Psychosocial characterization of a group of pregnant adolescents from Campechuel.Rev municipality. Novelties in population.

6. Cortés Alfaro A, Chacón O’Farril D, Álvarez García AG, Sotonavarro Gómez Y (2015) Early maternity: impact on family health and society. Rev Cubana Medicina Integral Integral 31(3): 376383.
7. Garcia Odio AA, González Suárez M (2018) Risk factors associated with pregnant teenagers. Rev Medical Sciences 22(3).

8. Chacón O'Farril D, Cortés Alfaro A, Álvarez García AG, Sotonavarro Gómez Y (2015) Pregnancy in adolescence, its family repercussion and in society. Rev Cubana Obstet Ginecol 41(1): 50-58.

9. Gálvez Espinosa M, Rodríguez Arévalo L, Rodríguez Sánchez CO (2016) Pregnancy in adolescence from the perspective of health and society. Rev Cubana Med Gen Integr 35(2).

10. Toro Huamanchumo CJ, Torres Román JS, Bendezu Quispe G (2016) Pregnancy in adolescence: addressing the epidemic. Rev Cubana Med Gen Integr 35(4).

11. González Cruz M, León Acebo M, Pérez Nápoles ML, Pérez Manzano JL, Aponte Ramírez L (2016) Prenatal alterations and knowledge about biosocial risks in pregnant adolescents. Rev Electron 41(8).

12. Pérez Estrada LE, Tamayo Ortiz A, Santisteban Cedeño LY, Mariño Pérez Y, Pérez Estrada, ME (2016) Perception of risk on pregnancy in ninth grade adolescents. MULTIMED Rev Médica Granma 20(1).

13. Ramos Rangel Y (2016) Global self-esteem and maternal self-esteem in adolescent mothers. Rev Cubana Med Gen Integr 35(4).

14. Portela Sabari A, Carbonell Naranjo M, Hechavarría Torres M, Jacas García C (2016) Attention deficit hyperactivity disorder: some considerations about its etiopathogenesis and treatment. MEDISAN 20(4).

15. Prego Beltrán CE, Bordonado Bordonado O, de la Paz Estrada C, Reyes Espinosa G, Álvarez Diéguez AR (2010) Attention Deficit and Hyperactivity Disorder, Risk Factors. Polyclinic "Rolando Monterrey". Rev. Hosp. Psychiatric Hospital of Havana 7(3).

16. Rojas Reyes Y, Calzada Reyes A, Rojas Zuaznabar L (2010) Electroencephalographic differences in children with two subtypes of attention deficit hyperactivity disorder. Rev habanciencméd 9(4): 491499.

17. Ramírez Vázquez H (2016) Development of the child, effects of prematurity, premature children. MEDISAN 20(4): 559

18. Etchepareborda Máximo C, Díaz Stara (2009) Controversial aspects in attention deficit disorder. Updates in child neurology II. Medicine (buenos aires) 69(1): 51-63.

19. Getahun D, Rhoads GG, Kitaw Demissie, Shou En Lu, Quinn VP, et al. (2012) In Utero Exposure to Ischemic-Hypoxic Conditions and Attention-Deficit / Hyperactivity Disorder. Pediatrics 131(1): 53-61. 
20. Premature children are at increased risk for cognitive, motor and behavioral difficulties.

21. Arnedo ML, Torres C (1995) Attention deficit hyperactivity disorder In: Gómez MR, Montilla J, Nieto M, (Eds) Neurology and pediatric neuropsychology. Jaén: Instituto Estudios Giennenses pp. 1449-1475.

22. Aguiar Aguiar G, Mainegra Fernández D, García Reyes O, Hernández Fonticiella Y (2016) Diagnosis in children with autism spectrum disorders in their development in textual comprehension. Rev Medical Sciences 20(6): 63-71.

\section{ISSN: 2574-1241}

DOI: 10.26717/BJSTR.2019.18.003211

Alba Cortes Alfaro. Biomed J Sci \& Tech Res

(C) $($ ) This work is licensed under Creative

Submission Link: https://biomedres.us/submit-manuscript.php
23. Biasutti de Oliveira LD, Days of Oliveira R, Serrano Enciso J, NakamuraPalacios EM (2016) Clinical application of the scale of autism in children. Rev Cubana Pediatr 88 (4): 406-416.

24. Hernández Ulloa E, Alfonso Hernández L (2015) Formative experience in school children with attention deficit hyperactivity disorder. Medimay 21(1).

25. Almaguer Brito L, García Silva L, Aguilera González MO, García Santiesteban JL, Gómez García K (2014) Attention deficit hyperactivity disorder in schoolchildren in the municipality of Puerto Padre. 39(9).

$\begin{array}{ll}\text { BIOMEDICAL } & \text { Assets of Publishing with us } \\ \text { RESEARCHES } & \text { - Global archiving of articles } \\ & \text { - Immediate, unrestricted online access } \\ & \text { - Rigorous Peer Review Process } \\ \end{array}$

